\section{Nigerian neonatologists per- ception and experience with retinopathy of prematurity}

\author{
Adedayo Adio, ${ }^{1}$ Sadiat Saka-Eletu \\ Aliyu, ${ }^{2}$ Aliyu Hamza Balarabe, ${ }^{2}$ \\ Kehinde Mosudi, ${ }^{2}$ Dupe Ademola- \\ Popoola, ${ }^{3}$ Teslim Lawal ${ }^{4}$ \\ ${ }^{1}$ Children's Eye Clinic, Department of \\ Ophthalmology, University of Port \\ Harcourt Teaching Hospital, Rivers \\ State; ${ }^{2}$ Department of Ophthalmology, \\ Federal Medical Center, Kebbi, Kebbi \\ State; ${ }^{3}$ Department of Ophthalmology, \\ University of Ilorin \& University of \\ Ilorin Teaching Hospital, Kwara State; \\ ${ }^{4}$ Department of Pediatrics, Federal \\ Medical Center, Kebbi, Kebbi State, \\ Nigeria
}

\section{Abstract \\ Background: Retinopathy of} Prematurity (ROP) is an avoidable condition that affects premature infants exposed to oxygen stresses at or soon after birth. In low- and middle-income countries, like Nigeria, neonatal mortality rates are high and very few infants live to develop ROP. With recent better care, ROP is now being diagnosed.

Objective: This study aimed to characterize what Nigerian neonatologists understand about ROP.

Methods: At a joint meeting of Nigerian pediatric ophthalmologists and neonatologists in Kebbi State held 26-29 July 2018, questionnaires collected attendees' perspective and experience with ROP including causes, risk factors and experiences.

Results: Fifty-one neonatologists out of 71 returned a completed questionnaire (response rate: $71.8 \%$ ). The male:female ratio was $1: 1.8$, and approximately $40 \%$ were aged $41-50$ years $(n=20,39.22 \%)$. Only $3(6.39 \%)$ had experience managing infants below $500 \mathrm{~g}$ that survived. A majority managed babies with a mean weight of $913 \mathrm{~g} \pm 300.37$ and age of 27.87 weeks \pm 2.37 . Most had no access to oxygen monitors ( $\mathrm{n}=39,78 \%$ ). Most had 10 babies to one monitor and used average settings of 90$95 \%$. One third had seen a case of ROP $(n=15,29.41 \%)$. Only 5.88\% $(n=3)$ were unaware of uncontrolled oxygen use as a risk factor. Only $4(8.89 \%)$ had a functional screening team. None were aware of local screening guidelines.

Conclusions: Regular educational programs, collaborative clinical presentations and webinars about ROP targeted at the neonatologists and parents, including establishment of screening programs across country will likely help reduce the burden of ROP blindness in Nigeria.

\section{Introduction}

Control of blindness in children is of utmost priority for the World health Organization. ${ }^{1}$ One of the causes all over the world is Retinopathy Of Prematurity (ROP), which is an abnormal proliferative retinopathy that develops in preterm infants born before 32 weeks of gestation or those weighing less than $1500 \mathrm{~g}$ at birth or those that may have received $100 \%$ oxygen therapy in the neonatal unit. ${ }^{2}$ It is a disorder of the developing retinal vessels seen in premature infants that occurs from interruption of the normal progression of vessels to the peripheral retina. ${ }^{2}$ Unless these babies are carefully managed, they can become visually impaired or blind. ${ }^{3}$

However, the survival rate of premature infants is increasing worldwide; ROP is becoming an important cause of preventable blindness. ${ }^{3-5}$ At least 50,000 children are blind due to ROP throughout the world. ${ }^{5-7}$ The prevalence and contribution of ROP to causes of blindness in children in most parts of Nigeria is yet to be determined ${ }^{7}$ but pockets of studies show it is already happening in some areas, ${ }^{8}$ and not yet a significant problem in others. ${ }^{3}$ This may therefore be following a regional pattern as described in other climes. ${ }^{3,7-12} \mathrm{~A}$ blind school study in North East Nigeria recorded an incidence of $0.5 \%{ }^{13}$ while in South West Nigeria, was $5.5 \% .^{14}$

Although the number of infants blinded by ROP is relatively small, but the duration of blind years experienced by such affected babies is significant therefore early identification and timely treatment where available cannot be underscored. ${ }^{3,15}$ It is essential that healthcare professionals such as neonatologists, general pediatricians and pediatric ophthalmologists and retina surgeons know how and when to screen for and treat ROP. ${ }^{16-18}$ Early identification and recognition of ROP by screening has therefore been recommended as a standard practice globally for timely intervention of treatable ROP. ${ }^{9}$ The disease is not present at birth but develops as the preterm child grows. Although historically the survival rates of such children is very low, due to the emergence of the subspecialty of neonatology, which gives better training in the care of preterm infants and more awareness of how to better manage them, smaller ones now tend to survive more. Therefore, it is anticipated that in developing countries in Africa, especially
Correspondence: Adedayo Adio, Children's eye clinic, Department of Ophthalmology, University of Port Harcourt Teaching Hospital, Rivers State, Nigeria.

Tel.: +2348033108139

E-mail: drdayoadio@yahoo.com

Key words: Retinopathy of prematurity; screening guidelines; oxygen; neonatologists; Nigeria.

Contributions: The authors contributed equally.

Conflict of interest: The authors declare no potential conflict of interest.

Availability of data and materials: All data generated or analyzed during this study are included in this published article.

Ethics approval and consent to participate: This study was approved by the ethics committee of the Federal Medical center, Kebbi state with a study approval number HREC Reg no 105:27/2018.

Informed consent: Consent for this study was given verbally after addressing respondents about the study.

Received for publication: 25 October 2019.

Revision received: 23 March 2021.

Accepted for publication: 19 April 2021.

This work is licensed under a Creative Commons Attribution NonCommercial 4.0 License (CC BY-NC 4.0).

${ }^{\circ}$ Copyright: the Author(s),2021

Licensee PAGEPress, Italy

Journal of Public Health in Africa 2021; 12:1289 doi:10.4081/jphia.2021.1289

Nigeria, there might be an epidemic very soon of ROP, such as is being experienced in Latin America currently. ${ }^{8}$ Improvements in maternal and neonatal health have been found to be responsible for the improved outcomes and only equal investment in and maintenance of national ophthalmic care infrastructure can help in the reduction of the burden of avoidable blindness. ${ }^{8}$

The standard method for screening and diagnosis of ROP is by bedside indirect ophthalmoscopy to detect early progressive disease after a few weeks of life as described in the initial screening guidelines given by the American Academy of Pediatrics (AAP), and American Association for Pediatrics and Strabismus (AAPOS). ${ }^{16}$ These guidelines recommend screening for infants with a birth weight of less than $1500 \mathrm{~g}$ or a gestational age of 32 weeks or less and selected infants with a birth weight 1500 and $2000 \mathrm{~g}$ or gestational 
age of more than 32 weeks with an unstable clinical course, including those requiring cardio-respiratory support and those who are believed by their attending pediatrician or neonatologist to be at high risk, should have retinal screening examination performed after pupillary dilation using binocular indirect ophthalmoscopy to detect retinopathy of prematurity (ROP).,18-21

Neonatologists and pediatricians play a vital and pivotal role in identification and referral of preterms especially the ones at risk to the ophthalmologists since the children are primarily under their care. Thus, it is essential that neonatologists/pediatricians should be aware of ROP screening guidelines, risk factors, referral indications and resource availability. ${ }^{15-17,20}$ The present study aimed to characterize the level of experience with ROP amongst Nigerian neonatologists and their perceptions about whether there were screening programs in place in our hospitals.

\section{Materials and Methods}

\section{Ethical considerations}

This study was approved by the ethics committee of the Federal Medical center, Kebbi state with a study approval number HREC Reg no 105:27/2018. Consent for this study was given verbally after addressing respondents about the study. The understanding was anyone who accepted to fill the questionnaires had by that action given consent. Forms collected to contact information for respondents and were crosschecked for de- after checking that all aspects of the questionnaires returned were properly filled. Just before the joint session, the de-identified questionnaire was filled by the neonatologists who attended the meeting and retrieved.

\section{Study design}

At the $3^{\text {rd }}$ Annual meeting of the Nigerian Society of Neonatologists
(NISOMN) which was held in Birnin-Kebbi in Kebbi state, Nigeria 26-29 July 2018, a joint session with Nigerian Pediatric Ophthalmology and Strabismus Society (NIPOSS) was held to discuss retinopathy of prematurity and the role of pediatricians and pediatric ophthalmologists in its prevention and management so as to prepare all stakeholders adequately for wholistic management of this highly preventable blinding condition. A questionnaire was offered to attendees of the meeting that asked questions about attendees' perspective and experience with ROP including the causes of prematurity, its risk factors and other experiences that they may have observed in their practice over the years.

A total of 150 neonatologists/and general pediatricians who practice neonatology registered to attend that meeting. The total number of active pediatricians in Nigeria documented in 2011 was 476 in number. ${ }^{22}$ The current number of neonatologists in Nigeria is not known or documented in available literature.

\section{Data analysis}

The data generated was managed with Microsoft Excel 2016 (Microsoft Corporation, Redmond, Washington, United States) and Epi info version 7.02 (Centers for Disease Control, Atlanta, Georgia, United States). Chi square was used to determine associations and Students' t- test was used to compare two means. A p-value of $<0.05$ was taken as significant.

\section{Results}

\section{Socio-demography of neonatologists}

Fifty-one neonatologists responded out of 71 giving $71.8 \%$ response rate. The age group of 41-50 years were among the highest number of respondents representing more than a quarter of the total number $(n=20,39.2 \%)$ while those older than 60 were the fewest $(n=3,5.9 \%$, Table 1$)$.

There was female preponderance $(n=32,62.8 \%)$. Male: female ratio of $1: 1.7$ (Table 1).

\section{Geographical spread}

The neonatologists were from all geopolitical zones of Nigeria with a relatively higher number from Abuja $(n=7,14.6 \%)$. Fifteen $(31.3 \%)$ were from the Northwest (NW) Geopolitical Zone (GPZ) of Nigeria with $10(20.8 \%)$ from Kano and Kaduna, all within this GPZ. Five each were from Northcentral, North East and South west GPZ respectively while 7 and 4 people each were from South South and South East GPZ respectively (Table 2).

\section{Neonatology experience}

In terms of years of practice, as a medical professional, majority have practiced for at least $10-20$ years $(n=23,45.1 \%)$. Only one person had over 30 years practice (7.84\%). Only 1 had training outside Nigeria. (2.1\%). Basically, all had their professional training in Neonatology within Nigeria.

The smallest birth weight of preterm babies ever managed that survived by the respondents ranged from between $300 \mathrm{~g}$ to $2000 \mathrm{~g}$ with a mean of $913 \mathrm{~g} \pm 300.37$. Majority had only experienced managing preterm babies weighing between 700-900g $(n=28,46.8 \%)$. Only 3 have ever had experience managing babies below $500 \mathrm{~g}$ and these babies survived (6.4\%, Table 3 ).

The earliest age of preterm that was ever cared for that survived had a mean of 27.87 weeks \pm 2.37 with a range of between 24 weeks and 34 weeks age of preterm.

Statistically significant association was observed between years of practice as a doctor and smallest baby age ever taken care of $(p=0.697$, Table 4).

But when length of experience was compared with smallest baby ever managed that survived, it was found that a statistically significant higher mean of smallest birth weight in grams was observed in doctors

Table 1. Age and Gender distribution of neonatologists between $26^{\text {th }}$ and $29^{\text {th }}$ July 2018 in Birnin-Kebbi, Nigeria at a joint conference between them and ophthalmologists.

\begin{tabular}{|c|c|c|c|c|}
\hline Age & $\begin{array}{c}\text { Male, } \mathrm{n}=19 \\
\% 37.25\end{array}$ & $\begin{array}{c}\text { Female, } \mathrm{n}=32 \\
\% 62.74\end{array}$ & Frequency & $\begin{array}{c}\text { Percentage (\%) } \\
n=51\end{array}$ \\
\hline $21-30$ & 2 & 68 & 15.7 & \\
\hline $31-40$ & 2 & 79 & 17.6 & \\
\hline $41-50$ & 9 & 10 & 19 & 37.3 \\
\hline $51-60$ & 5 & 712 & 23.5 & \\
\hline$>60$ & 1 & 23 & 5.9 & \\
\hline Total & 19 & 32 & 51 & 100 \\
\hline
\end{tabular}


who have been in practice within previous 20 years compared to those whose practice is greater than 20 years $(865.0 \mathrm{~g}$ vs. $660.91 \mathrm{~g}$; $\mathrm{p}=0.05$, Table 3 ).

Most have experience with preterm babies between 26 and 28 weeks $(n=25$, $58.1 \%$, Table 4 ). Majority had been working in a Special Care Baby Unit/Neonatal Intensive Care Unit (SCBU/NICU) for up to 10 years $(n=31,63.3 \%)$.

Regarding whether there were dedicated oxygen monitors for each child in their SCBUs, it was negative in the majority of respondents $(n=39,78 \%)$. The location of their practice did not significantly affect this (Chi-Square $\left(\chi^{2}\right)=19.6$ p-value: 0.294 ). Eleven $(23.4 \%)$ of the respondents reported the availability of dedicated vital sign monitor per baby born premature, the monitors were mostly shared among several babies. The situation was not significantly different in any of the six geopolitical zones in Nigeria. On average there were between 15 number of preterms to one oxygen monitor in a third of those who had monitors $(n=11$, centers, 28.2\%). Two centers had more than 10 babies to one monitor.

The oxygen saturation kept in the practice of these neonatologists for these preterms was on average $90-95 \%$ $(n=21,70 \%)$. One respondent however admitted to using lower settings of $70-80 \%$ $(\mathrm{n}=1,3.3 \%)$.

Majority of the 38 preterm babies that survived were females $(n=25,65.8 \%)$ with male: female ratio of 1:1.9.

\section{ROP experience}

Most had heard about ROP $(n=50,98.0 \%)$. Only one never heard about it. Most understood what ROP was $(\mathrm{n}=44,93.6 \%)$ with a few respondents referring to it as cancer of the eye $(n=3,6.38 \%)$. Experienced neonatologists however were able to differentiate ROP from cancer of the eye however it was not statistically significant [Chi-Square $\left(\chi^{2}\right)=1.336$, p-value: $0.513]$.

Only a third had actually come across a case of ROP in their practice ( $n=15,29.4 \%$ ). Though older neonatologists were more likely to have seen cases of ROP in their practice, it was not statistically significant (Chi-Square $\left(\chi^{2}\right)=2.04$, p-value: 0.153 ).

Majority had never had a case of ROP among their preterms $(n=36,70.6 \%)$.

Of those who had encountered a case of ROP, almost $10 \%$ of respondents stated that they had seen up to 4 babies with ROP in their practice $(7.84 \%)$. A statistically significant higher mean number of cases had been seen since start of practice among doctors who had practiced for more than 20 years compared to those whose practice is less or equal to 20 years (4.08 vs. $0.41 ; \mathrm{p}=0.05)$.

Only 3 respondents were not aware that prematurity was an important risk factor $(5.88 \%)$ while 17 did not know that low birth weight was important (33.3\%). However, these were not statistically significant.

Up to 3 respondents were also not aware that high uncontrolled oxygen exposure may significantly contribute to the development of ROP (5.88\%). A quarter of the respondents were not aware of sepsis as a risk factor $(25.5 \%)$.

It was however unanimous that history of delivery by caesarian section along with history of instillation of breastmilk into the eyes were not significant in the development of ROP.

Three quarters of the neonatologists understood what leukocoria was and were aware that ROP is a cause of leukocoria in preterm (n-37, 72.6\%) and confirmed that they have seen children with it.

Table 2. Comparison of number of respondent Nigerian Neonatologists with State of practice between 26th and 29th July 2018 in Benin-Kebbi, Nigeria at a joint conference between them and ophthalmologists.

\begin{tabular}{|c|c|c|c|c|}
\hline State of Practice & $\begin{array}{l}\text { Frequency, } \\
\qquad \mathrm{n}=48 *\end{array}$ & Percentage (\%) & Geo-political zone & Freq. \% \\
\hline $\begin{array}{l}\text { Abuja } \\
\text { Kaduna } \\
\text { Sokoto } \\
\text { Kebbi } \\
\text { Kano } \\
\text { Zamfara }\end{array}$ & $\begin{array}{l}7 \\
5 \\
5 \\
3 \\
1 \\
1\end{array}$ & $\begin{array}{c}14.58 \\
10.42 \\
10.42 \\
6.25 \\
2.08 \\
2.08\end{array}$ & $\begin{array}{l}\text { FCT } \\
\text { NW } \\
\text { NW } \\
\text { NW } \\
\text { NW } \\
\text { NW }\end{array}$ & $\begin{array}{l}14.58 \\
31.25\end{array}$ \\
\hline Kogi & 1 & 2.08 & $\mathrm{NC}$ & 10.41 \\
\hline $\begin{array}{l}\text { Nassawara } \\
\text { Plateau } \\
\text { Niger }\end{array}$ & $\begin{array}{l}1 \\
1 \\
2\end{array}$ & $\begin{array}{l}2.08 \\
2.08 \\
4.17\end{array}$ & $\begin{array}{l}\mathrm{NC} \\
\mathrm{NC} \\
\mathrm{NC}\end{array}$ & \\
\hline $\begin{array}{l}\text { Gombe } \\
\text { Bornu }\end{array}$ & $\begin{array}{l}1 \\
4\end{array}$ & $\begin{array}{l}2.08 \\
8.33\end{array}$ & $\begin{array}{l}\mathrm{NE} \\
\mathrm{NE}\end{array}$ & 10.41 \\
\hline $\begin{array}{l}\text { Bayelsa } \\
\text { Cross river } \\
\text { Delta }\end{array}$ & $\begin{array}{l}3 \\
2 \\
2\end{array}$ & $\begin{array}{l}6.25 \\
4.17 \\
4.17\end{array}$ & $\begin{array}{l}\text { SS } \\
\text { SS } \\
\text { SS }\end{array}$ & 14.59 \\
\hline $\begin{array}{l}\text { Enugu } \\
\text { Ebonyi }\end{array}$ & $\begin{array}{l}3 \\
1\end{array}$ & $\begin{array}{l}6.25 \\
2.08\end{array}$ & $\begin{array}{l}\text { SE } \\
\text { SE }\end{array}$ & 8.32 \\
\hline Lagos & 5 & 10.42 & SW & 10.42 \\
\hline
\end{tabular}

N- North, S-South, W-West, E-East, FCT Federal Capital Territory SS-South South, SE-South East, SW-South West, NE-North East, NW-North West. ${ }^{*} 2$ out of the 51 respondents declined.

Table 3. Association between years of practice of Nigerian neonatologists and premature infant with smallest birth weight ever managed between $26^{\text {th }}$ and $29^{\text {th }}$ July 2018 in Birnin-Kebbi, Nigeria at a joint conference between them and ophthalmologists.

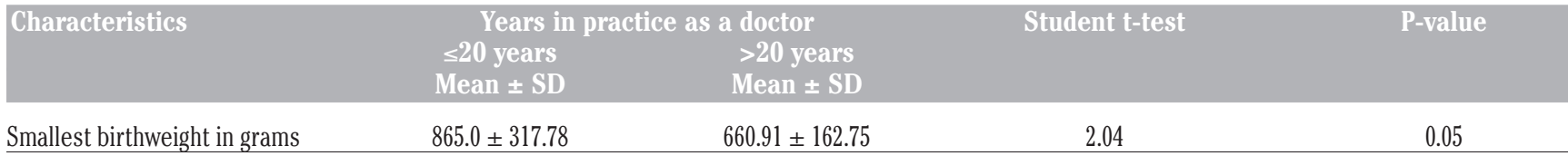

Statistically significant $(\mathrm{p}<0.05)$. SD: Standard deviation. 
$(n=34,66.7 \%)$. However up to $30 \%(n=14$, $27.5 \%$ ) said they had never actually seen leukocoria.

Thirty -seven respondents (72.6\%) believed ROP could still be treated once it had developed. Forty-eight respondents believed that without treatment, it could lead to blindness ( $\mathrm{n}=48,94.1 \%)$.

Two respondents however stated it would not cause blindness even if not treated $(5.88 \%)$. Length of experience however did not affect these responses in any significant way [Chi-Square $\left(\chi^{2}\right)=0.005$, p-value: 0.944].

However, when asked whether it could lead to death, 30 of them said no $(58.8 \%)$ while up to a quarter of those who responded said yes, it could, $(n=11,21.6 \%)$. Chi square analysis however showed this was not significant even when compared with length of experience of the neonatologists $\left(\chi^{2} 0.94, p=0.332\right)$.

\section{Screening and referral for ROP}

All equally agreed unanimously that it was important to screen for retinopathy of prematurity.

In relation to when screening should be done, a little less than half $(n=24,47.1 \%)$ agreed that it should be within 1 month after birth, $13.7 \%$ had no idea when this should be, $15.69 \%$ however felt it should be immediately after birth.

As per who does the ROP screening, majority felt the Ophthalmologist should be in charge of this $(n=37,80.4 \%$, Table 5).

Most of the respondents said they will definitely advice a referral to an Ophthalmologist once they see leukocoria in a child with a history of prematurity $(\mathrm{n}=31,75.6 \%)$.

Only 4 (7.8\%) Neonatologists present had an ROP team in place doing screening in their centers (Table 5). ROP screening teams as at the time of writing this paper was located only in the South East and South West GPZ.

The location of practice did not significantly affect whether an ROP screening team was present or not [Chi-Square $\left(\chi^{2}\right)$

Table 4. Smallest gestational age of premature infants ever managed by Nigerian neonatologists between 26th and 29th July 2018 in Birnin-Kebbi, Nigeria at a joint conference between them and ophthalmologists.

\begin{tabular}{|c|c|c|}
\hline Smallest baby age in weeks & $\begin{array}{c}\text { Frequency } \\
n=43\end{array}$ & Percentage \\
\hline 24 & 2 & 4.65 \\
\hline 25 & 4 & 9.30 \\
\hline 26 & 10 & 23.3 \\
\hline 27 & 7 & 16.3 \\
\hline 28 & 8 & 18.6 \\
\hline 29 & 4 & 9.30 \\
\hline 30 & 3 & 6.98 \\
\hline 31 & 0 & 0 \\
\hline 32 & 3 & 6.98 \\
\hline 33 & 1 & 2.33 \\
\hline 34 & 1 & 2.33 \\
\hline Mean & \multicolumn{2}{|c|}{$27.87 \pm 2.37$ weeks } \\
\hline
\end{tabular}

$=25.41$ p-value: 0.086$]$.

All agreed that both the Ophthalmologists and the Neonatologist should be in the screening team while majority of those who responded agreed about the inclusion of nurses into the team $(n=29,93.55 \%)$.

Two respondents however suggested that parents could also be part of the team. None were aware if there were any particular screening guidelines in place for Nigeria.

\section{Discussion}

Neonatology is a burgeoning subspecialty in Nigeria and because of this many more babies delivered far too early now are getting better care and surviving more. Even though most are working under lessthan-ideal circumstances, many Nigerian neonatologists have fair understanding of the complications arising from unmonitored use of oxygen but still have some ways to go to gain ownership of the screening process for Retinopathy of prematurity. As at the time this study was carried out, less than $10 \%(8.89 \%)$ had any screening going on in their centers.

However, retinopathy of prematurity is becoming diagnosed in Nigeria more and more in recent times with a small but significant number showing up in our children eye clinics with blinding disease. ${ }^{23}$ This is doubly tragic as it means firstly that enough is not being done to ensure these children don't go blind and secondly that though we have Pediatricians/neonatologists taking care of these children from the beginning from when they were born too early, there may have been insufficient focus/efforts directed to look for ROP among those who have risk factors so as to ensure this does not happen and if it does, to call in Ophthalmologists who will look for and treat it before it turns to blindness.

Table 5. Presence of retinopathy of prematurity screening teams within geopolitical zones in Nigeria between $26^{\text {th }}$ and $29^{\text {th }} \mathrm{July}^{2018}$ in Birnin-Kebbi, Nigeria at a joint conference between them and ophthalmologists.

\begin{tabular}{|c|c|c|c|c|c|}
\hline Geopolitical zone & $\begin{array}{r}\text { Do have y } \\
\text { in } \\
\text { Yes, Freq }(\%)\end{array}$ & $\begin{array}{l}\text { ing team } \\
\text { re? } \\
\text { No, Freq (\%) }\end{array}$ & Total & df & $\begin{array}{c}\text { Chi-Square }\left(\chi^{2}\right) \\
\text { (p-value) }\end{array}$ \\
\hline $\mathrm{NC}$ & $0(0.0)$ & $11(26.83)$ & $11(24.44)$ & 5 & $19.28(0.002)$ \\
\hline $\mathrm{NE}$ & $0(0.0)$ & $5(12.20)$ & $5(11.11)$ & 5 & $19.28(0.002)$ \\
\hline NW & $0(0.0)$ & $15(36.59)$ & $15(33.33)$ & 5 & $19.28(0.002)$ \\
\hline SE & $2(50.0)$ & $2(4.88)$ & $4(8.89)$ & 5 & $19.28(0.002)$ \\
\hline SS & $0(0.0)$ & $5(12.20)$ & $5(11.11)$ & 5 & $19.28(0.002)$ \\
\hline SW & $2(50.0)$ & $3(7.32)$ & $5(11.11)$ & 5 & $19.28(0.002)$ \\
\hline
\end{tabular}

Statistically significant $(\mathrm{p}<0.05) \mathrm{df}=$ degree of freedom. NC: North Central, NE: North East, NW: North West, SE: South East, SS: South South, SW: South West. 
It is not clear why this is so. Some of the reasons could be lack of attention to the possibility of the disease condition by stakeholders and lack/paucity of equipment to screen the premature baby with. Before now, a significant number of premature/small babies did not stay alive long enough to develop the disease. ${ }^{24,25}$ But this seems to be changing due to more multiple pregnancies from assisted delivery being more commonplace in developing countries and better facilities in place to save both mother and child in some places.

Because of this possibility that more cases of ROP could start to show up, awareness of the ROP screening activities in Nigeria have begun to increase very slowly over the last two decades from the first published work in Nigeria by Baiyeroju. ${ }^{14}$ This may have been the only center screening that period as documented by the authors. In this study, only one developed ROP though the 'preemie' died shortly after. Many more cases were not found because a lot of babies died very early after birth. ${ }^{26}$ Following that period, very few centers were involved in screening for ROP over the next 2 decades. 3,26,27 In the last 2-3 year however, routine screening is now taking place in some centers. ${ }^{8,15,28,29}$ Though only 4 of the neonatologists that responded as shown in this paper were involved in ROP screening at the time of writing this article (Table 5).

The recent sub-specialization of Pediatricians to Neonatology which was designed to improve the practice has led to improved care of this group of babies leading to better outcomes and more babies surviving. ${ }^{25,30-32}$ The improved neonatal technology and human capacity at public neonatal units has particularly led to more premature baby survival in parts of Nigeria especially among those with birth weight under $1000 \mathrm{~g}$ and even below $500 \mathrm{~g}$ which previously were not living long enough to develop ROP.

Although it now appears that Neonatologists are more interested in ROP (given the high response rate in this study), ROP is often not in the fore front of their consideration as shown by the varied responses to level of ROP screening routinely done among the participants (mostly from the northern part of the country) they are expected to champion the cause of ROP being the primary caregiver of these children.and as such should be well informed about ROP. Ideally, they should be the drivers of the move to examine these children for ROP.

Since purchase of screening, diagnostic and other cost intensive equipment have been found to be the difficulty in lowincome countries, preventive measures that are affordable have been found to be comparatively useful if employed by clinicians working in these areas. For example, some studies including a meta- analysis have described the use of oral and intra-muscularly administered vitamin A (retinol) supplements in the reduction of severe ROP and bronchopulmonary dysplasia (BPD) in preterm. ${ }^{32-35}$ Vitamin A reportedly plays a critical role in alveolar epithelial cell growth, differentiation, development, and maintenance as well as lung injury prevention in animal models. ${ }^{33}$

In addition to limiting use of supplemental oxygen, use of human breast milk of mothers who have been given omega 3 fatty acids has been found useful as a means of preventing severe ROP but it still requires some more study. ${ }^{33}$ This has greater impact in very low birthweight preterm $(<25$ weeks gestation age) who have very low stores of vitamin $\mathrm{A}$ at birth.

Dosages used were 5,000 International Units (IU) of vitamin A supplement (watersoluble retinyl palmitate) three times per week for 4 weeks by intramuscular injection. This repeated IM injections have made the use a little unpopular and oral routes have been tried- 5,000 IU/kg of supplemental vitamin A (form not stated) was administered orally each day till day 28 . However, the issue with this is the less than effective absorption of vitamin A through the immature enteral route of the preterm. ${ }^{33}$ However Vitamin A was responsible for up to $80 \%$ reduction in incidence of any stage of $\mathrm{ROP}^{35}$ and so it is pertinent that research into this be carried out in our low-income countries to see if the same outcomes will be seen. In addition, in recent years, a number of researches has highlighted the potential of new technologies for ROP screening as telemedicine especially where access to skilled manpower to examine the babies are lacking (trained neonatologists or other cadre of trained staff could take fundus pictures and send through this means to a remote expert for interpretation). ${ }^{36,37}$

Low-cost smartphone-based systems which are light weight, cost-effective, user friendly and can take high-quality widefield fundus photographs for bedside documentation of ROP in NICUs can be a boon in low resource settings. ${ }^{37-39}$ Even artificial intelligence using a system with extremely high sensitivity, in the next future could contribute to widen substantially, access to ROP screenings in limited-resource settings. It has been explored and may have a future expanded role in diagnosis of plus disease..$^{40}$

Though this study was done during a national meeting of Neonatologists with a significantly large attendance from hospi- tals in the Northern part of Nigeria, the responses however represent the position of a significant number of Neonatologists and may therefore be a true reflection of the situation of ROP care in the whole country. The apparently low level of awareness is still obvious and similar when compared with another earlier study of this group ${ }^{24}$ and may contribute to the inadequate stocking of basic pediatric and ROP screening equipment like oxygen blenders, CPAP (Continuous Positive Airway Pressure machine) and Binocular indirect ophthalmoscopes (BIOs) required in most centers across Nigeria. This apparent apathy towards screening for ROP may be because other probably more urgent challenges faced in SCBUs including neonatal asphyxia, respiratory distress, apneic attacks, anemia and jaundice appear more readily visible to both neonatal staff and caregivers. But this on its own does not justify poor and erratic supply of screening, diagnostic and therapeutic equipment. Equipment such as pulse oximeters are extremely important in the monitoring of the $\mathrm{SpO} 2$ of these preterm babies seeing it is a modifiable risk factor to developing ROP. In a study looking at its use in low resource settings like Nigeria where it may not be available for each baby, it is advocated to at least monitor them more than 4.7 times a day to be able to better evenly maintain their $\mathrm{SpO} 2 .^{29}$

Several neonatologists reported not to have had a case of ROP in their practice, this is not unexpected because screening was likely not done, leukocoria which is the only 'visible' sign of ROP only develops well after discharge from SCBUs and many surviving premature infants who are often referred from places far away from the hospitals are already lost to follow up only to present later in infancy to the eye clinics (not to pediatric clinics in most cases) with vision problems. The neonatal unit may not get the information about the visual status of the children unless caregivers vigorously make attempts to attend follow up (a rarity in developing countries). ${ }^{41}$

Recently, the feedback from Ophthalmologists to neonatal units about the few children that have developed blinding ROP seem to have helped sustain the screening for ROP along with interaction in social media groups focused on sharing information on any new case of ROP discovered.

Screening for ROP however is plagued by gaps in education of parents, ${ }^{42}$ and of human resources especially in neonatal units, maintenance of resources available to neonatal units across the country and the inadequate number of neonatal staff 26,43 which makes ROP screening seem a further 
strain on the already over worked neonatal units many of whom are just managing to maintain a balance of staff to patient ratio at a barely functional level especially since the economic challenge of the last decade.

The need for focused training on ROP during ophthalmic and pediatric residency training and targeted training of trainers is emphasized by the inadequate knowledge about ROP risk factors, course of ROP, screening guidelines and the poor prognosis of cicatricial ROP in this study which is not significantly different from earlier studies. $^{43,44}$

It is encouraging and noteworthy that the majority of neonatologists in this study believe in the need for ROP screening, this should be explored for the development of ROP screening and subsequent establishment of national and regional screening guidelines in Nigeria which are being currently developed.

The Ophthalmologist (especially Pediatric) might have to play a more definite role to bring all critical stakeholders on board. However, for the drive for ROP screening to be sustained, it must eventually be championed by neonatal staff including the nurses and embraced by Ophthalmologists in a structured and deliberate way by getting involved in screening these 'preemies' and also larger babies who may have had a rough postnatal course. ${ }^{43}$ These initiatives will quickly help in the development of national screening guidelines that will further encourage more emphasis on ROP in the training of pediatricians and neonatologists. The recent increase in cases found both in missed ROP blindness in outpatient clinics and in those deliberately screened for ROP points to an impending epidemic that must be stemmed. ${ }^{28}$ Improving the current knowledge and awareness of neonatologists in this area for example, through widespread educational programs, grand rounds and clinical presentations are an effective way to do this. ${ }^{45}$ All hands must be on deck.

\section{Limitations}

Out of those that attended the conference, only 4 neonatologists were actively involved with screening but due to the anonymous nature of the questionnaires, one is not sure if they are from one center or from different centers. However, ROP screening was actually only going on at University of Port Harcourt Teaching Hospital, University of Ilorin Teaching Hospital, University College Hospital, National hospital, Gwagwalada, University of Benin teaching hospital and University of Lagos Teaching hospital all in Nigeria as at the time of writing this paper.

\section{Conclusions}

A large number of Nigerian Neonatologists (about two-thirds of respondents in this cohort) were well experienced in the SCBUs having been practicing there for at least 5 years. The subsequent responses showed how in spite of improvement in survival of extreme preterm with birth weight $1000 \mathrm{~g}$ or less, ROP was yet to be a major consideration in their practice. This is typically because the retina is not in clear view and also because most of the babies who develop ROP blindness do so after discharge from the SCBU where the disease began. It is therefore expedient that active efforts are made to build up comprehensive teams of all stakeholders to develop guidelines and curb the menace of ROP blindness. In addition, more efforts are required to sensitize both Neonatologists and caregivers on the importance of screening in a consistent and systematic manner across the country while documenting, reviewing and comparing data collated across board. This will position Africa to be ready to minimize childhood blindness from ROP if similar efforts are made across continent.

\section{References}

1. Gilbert CE, Foster A, Negrel AD, Thylefors B. Childhood blindness: a new form of recording causes of visual loss in children. Bull World Health Organ 1993;71:485-9.

2. Olitsky SE, Nelson LB. Disorders of the eyes. In Nelson Textbook of Pediatrics, Behrman RE, Kliegman RM, Jenson HB, Eds. WB Saunders, Philadelphia, PA, USA, 17th edition, 2003: pp. 658891.

3. Adio AO, Ugwu RO, Nwokocha CG, Eneh AU. Retinopathy of Prematurity in Port Harcourt, Nigeria. ISRN Ophthalmology 2014;2014:481527.

4. Campbell K. Intensive oxygen therapy as a possible cause for retrolental fibroplasia. A clinical approach. Med J Australia 1951;2:48-50.

5. Kretzerand FL, Hittner HM. Retinopathy of prematurity: clinical implications of retinal development. Arch Dis Childhood 1988;63:1151-67.

6. Zin A, Gole GA. Retinopathy of prematurity-incidence today. Clin Perinatol 2013:40;185-200.

7. Gilbert C. Retinopathy of prematurity: A global perspective of epidemics, population of babies at risk and implications for early control. Early Hum Dev 2008;84:77-82.

8. Ademola-Popoola DS, Oluleye TS.
Retinopathy of prematurity in a developing economy with improving health care. Curr Ophthalmol Rep 2017;5:114-8

9. Solebo AL, Teoh L, Rahi J. Epidemiology of blindness in children. Arch Dis Child 2017;102:853-7.

10. Hariharan L, Gilbert CE, Quinn GE, et al. Reducing blindness from retinopathy of prematurity (ROP) in Argentina through collaboration, advocacy and policy implementation. Health Policy Plan 2018;33:654-65.

11. Arnesen L, Durán P, Silva J, Brumana L. A multi-country, cross-sectional observational study of retinopathy of prematurity in Latin America and the Caribbean. Rev Panam Salud Publica 2016;39:322-9.

12. Zin AA, Magluta C, Pinto MF, et al. Retinopathy of prematurity screening and treatment cost in Brazil. Rev Panam Salud Publica 2014;36:37-43.

13. Adekeye M. Causes of blindness in children in NE Nigeria: a blind school study [Dissertation for Masters degree in Community eye health, Department of Preventive Ophthalmology]. Institute of Ophthalmology, London, UK; 1996.

14. Baiyeroju-Agbeja AM, Omokhodion F. Screening for retinopathy of prematurity. Nig J Ophthalmol 1998;6:23-5.

15. Oluleye TS, Rotimi-Samuel A, Adenekan A. Mobile phones for retinopathy of prematurity screening in Lagos, Nigeria, Sub-Saharan Africa. Eur J Ophthalmol 2016;26:92-4.

16. Fierson WM; American Academy Of Pediatrics Section On Ophthalmology; American Academy of Ophthalmology; American Association for Pediatric Ophthalmology and Strabismus; American Association of Certified Orthoptists. Screening Examination of Premature Infants for Retinopathy of Prematurity.

Pediatrics 2018;142:e20183061. Erratum in: Pediatrics 2019;143.

17. Cryotherapy for Retinopathy of Prematurity Cooperative Group. Multicenter trial of cryotherapy for retinopathy of prematurity: preliminary results. Arch Ophthalmol 1998;106:471-9.

18. Clemett R, Darlow B. Results of screening low-birth-weight infants for retinopathy of prematurity. Curr Opin Ophthalmol 1999;10:155-63.

19. Rani P, Jalali S. Knowledge, attitude and practice study of retinopathy of prematurity amongst pediatricians attending a neonatal ventilation workshop in South India. World J Retina Vit 2011;1:9-13. 
20. Agarwal K, Jalali S. Classification of retinopathy of prematurity: from then till now. Community Eye Health 2018;31:S4-S7.

21. Jalali S, Azad R. It is time to take swift action. Community Eye Health 2018;31:S1-2.

22. Ekure EN, Balogun MR, Woo JG, et al. Pediatrician workforce in Nigeria and impact on child health. Niger J Paed 2013;40:112-18.

23. Gilbert C, Malik ANJ, Nahar N, et al. Epidemiology of ROP update-Africa is the new frontier. Semin Perinatol 2019;43:317-22.

24. Akinyemi JO, Bamgboye EA, Ayeni O. Trends in neonatal mortality in Nigeria and effects of bio-demographic and maternal characteristics. BMC Pediatr 2015;15:36.

25. Akombi BJ, Renzaho AM. Perinatal mortality in Sub-Saharan Africa: A meta-analysis of demographic and Health Surveys. Ann Glob Health 2019;85:106.

26. Ademola-Popoola D, Adesiyun O, Durotoye IA, Obasa TO. Screening program for retinopathy of prematurity in Ilorin, Nigeria: a pilot study. West Afr J Med 2013;32:281-5.

27. Al-Khaled T, Mikhail M, Jonas KE, et al. Global education network for retinopathy of prematurity (GEN-ROP). J Pediatric Ophthalmol Strabismus 2019;56:282-7.

28. Fajolu IB, Rotimi-Samuel A, Aribaba OT, et al. Retinopathy of prematurity and associated factors in Lagos, Nigeria. Peadiatr Int Child Health 2015;35:324-8.

29. Walker PJB, Bakare AA, Ayede AI, et al. Using intermittent pulse oximetry to guide neonatal oxygen therapy in a low- resource context. Arch Dis Child Fetal Neonatal Ed 2020;105:316-21.

30. Bhattacharya AA, Allen E, Umar N, et al. Monitoring childbirth care in primary health facilities: a validity study in Gombe state, Northeastern Nigeria. J Glob Health 2019;9:020411.

31. Olukade T, Yaya S. Bishwajit G, Uthman OA. Sociodemographic determinants of post-caesarean neonatal mortality in Nigeria. J Obstet Gynaecol 2019;29:1-7.

32. Darrow BA, Graham PJ, Rojas-Reyes MX. Vitamin A supplementation to prevent mortality and short- and long-term morbidity in very low birth weight infants. Cochrane Database Syst Rev 2016;8:CD000501.

33. Araki S, Kato S, Namba F, Ota E. Vitamin A to prevent bronchopulmonary dysplasia in extremely low birth weight infants: a systematic review and meta-analysis. PLoS One 2018; 13:e0207730.

34. Raghuveer TS, Zackula R. Strategies to prevent severe retinopathy of prematurity: a 2020 update and meta-analysis. Neoreviews 2020;21:e249-63.

35. Sun H, Cheng R, Wang Z. Early vitamin A supplementation improves the outcome of retinopathy of prematurity in extremely preterm infants. Retina 2020;40:1176-84.

36. Brady CJ, D'Amico S, Campbell JP. Telemedicine for Retinopathy of Prematurity. Telemed J E Health 2020;26:556-64.

37. Quinn GE, Vinekar A. The role of retinal photography and telemedicine in ROP screening. Semin Perinatol 2019;43:367-74.

38. Goyal A, Gopalakrishnan M, Anantharaman G, et al. Smartphone guided wide-field imaging for retinopathy of prematurity in neonatal intensive care unit - a Smart ROP (SROP) initiative. Indian J Ophthalmol 2019;67:8405.

39. Wintergerst MWM, Petrak M, Li JQ, et al. Non-contact smartphone-based fundus imaging compared to conventional fundus imaging: a low-cost alternative for retinopathy of prematurity screening and documentation. Sci Rep 2019;9:19711.

40. Tan Z, Simkin S, Lai C, Dai S. Deep learning algorithm for automated diagnosis of retinopathy of prematurity plus disease. Transl Vis Sci Technol 2019;8:23.

41. Farouk ZL, Muhammed A, Gambo S, et al. Follow-up of children with kernicterus in Kano, Nigeria. J Trop Pediatr 2018;64:176-82.

42. Eneriz-Wiemer M, Liu SD, Chu MCY, et al. Parents' knowledge and education of retinopathy of prematurity in four California neonatal intensive care units. Am J Ophthalm 2018;191:7-13.

43. Chan RV, Patel SN, Ryan MC, et al. The global education network for retinopathy of prematurity (gen-rop): development, implementation and evaluation of a novel tele-education system (an American ophthalmological thesis) Trans Am Ophthamol Soc 2015;113:T2. 44. Uhumwangho OM, Israel-Aina YT. Awareness and screening for retinopathy of prematurity among pediatricians in Nigeria. J West Afr Coll of Surgeons 2013;3:33-45.

45. Shah PK, Prabhu V, Karandikar SS, et al. Retinopathy of prematurity: Past, present and future. World J Clin Pediatr 2016;5:35-46. 